\title{
JOSÉ FÉLIX DE RESTREPO, EDUCADOR Y POLÍTICO
}

\author{
Jorge Tomás Uribe ${ }^{\mathbf{1}}$ \\ Universidad Pedagógica y Tecnológica de Colombia \\ Grupo de Investigación ILAC \\ jorgeturibe@hotmail.com
}

Recepción: 28/04/2010

Evaluación: $14 / 07 / 2010$

Aceptación: 16/07/2010

Artículo de Reflexión

\section{RESUMEN}

La trayectoria de José Félix de Restrepo fue excepcional, si se la compara con el resto de los ilustrados. Pedagogo y político, autor de iniciativas para la liberación de los esclavos, se salvó del cadalso durante la Reconquista española. Mientras en Santafé fracasaban las iniciativas para llevar los contenidos ilustrados al interior de las aulas, Restrepo, en el Colegio Seminario de San Francisco de Asís de Popayán, exponía esos contenidos a través de una metodología propia. Posteriormente, en su natal Antioquia, propuso iniciativas que dieron lugar a la liberación a la liberación de los esclavos. En tiempos de la Gran Colombia, continuó con sus iniciativas a favor de los esclavos y su participación en la conformación de la República fue determinante. El objetivo de este artículo es determinar la influencia que tuvo Restrepo como pedagogo y como político a través de la metodología propia de la historia de la educación y de las ideas. Las referencias teóricas más importantes se refieren a la presencia de la Ilustración en la Nueva Granada, especialmente la Ilustración Católica, y a la puesta en marcha del discurso liberal. Se trata de destacar la participación de Restrepo en la tarea de llevar los contenidos ilustrados al interior de las aulas y las iniciativas que buscaron la liberación de los esclavos en la República de Colombia.

Palabras clave: Ilustración, Pedagogía, Popayán, Provincia de Antioquia, Liberación de los esclavos, República de Colombia

1 Doctor en Ciencias de la Educación, profesor titular del la Universidad Pedagógica y Tecnológica de Colombia y profesor Doctorado en Ciencias de la Educación RUDECOLOMBIA, miembro del grupo de investigación Ilustración en América Colonial ILAC.

Rhela. Vol. 14. Año 2010, pp. $61-82$ 


\title{
JOSÉ FÉLIX DE RESTREPO, PROFESSOR AND POLITICIAN
}

\author{
Jorge Tomás Uribe \\ Universidad Pedagógica y Tecnológica de Colombia \\ ILAC Research Gruop \\ jorgeturibe@hotmail.com
}

\begin{abstract}
José Félix de Restrepo's career path was exceptional when compared with the rest of the enlightened figures. He was a pedagogue and a politician, the father of initiatives that lead to the enfranchisement of the slaves; he escaped the scaffold during the Spanish Reconquista. While the initiatives to introduce Enlightenment-based subject matters in the schools of Santafé were a failure, Restrepo expounded these subjects at the San Francisco de Asís Seminar College of Popoyán using a personal methodology. Later in his native Antioch he suggested initiatives in favour of the enfranchisement of the slaves. In the time of the Great Colombia he continued forwarding initiatives in favour of the slaves' enfranchisement and his participation in the construction of the Republic was decisive. This article aims at outlining Restrepo's influence as a pedagogue through his own methodology of the history of Education and ideas. The most important theoretical references are linked with the presence of the Enlightenment in New Granada, especially the catholic one, and the starting-off of a liberal discourse. We will emphasise Restrepo's participation in the task that consisted in introducing subjects influenced by the Enlightenment into schools as well as in his initiatives that attempted to give rise to the liberation of the slaves.
\end{abstract}

Key words: Enlightenment, Pedagogy, Popayan, Province of Antioch, Enfranchisement of the slaves, Colombian Republic.

2 DE RESTREPO, José Félix. Tomado de Biografía del doctor José Félix de Restrepo. Por OSPINA RODRIGUEZ, Mariano. (1888): http:biblioteca virtual -Antioquia. N. de a. edu.co. / pdf/11/11. La biografía citada carece de paginación. 


\section{INTRODUCCIÓN}

El periplo vital de José Félix de Restrepo no ofrece semejanzas frente a otros ilustrados criollos tales como sus alumnos de Popayán, o el resto de los sacrificados durante el régimen del terror. Mientras el desarrollo intelectual de estos estuvo amparado por la tutela que, desde Santafé, marcaron las reformas que en la enseñanza superior introdujeron o trataron de introducir figuras como Francisco Antonio Moreno y Escandón o José Celestino Mutis, Restrepo, desde Popayán, desarrolló una discreta labor que le permitió, sin embargo, influir sobre figuras de la importancia de Francisco José de Caldas, Camilo Torres, o Francisco Antonio Zea. Por otra parte, si en muchos casos, los ilustrados asimilaron mecánicamente los contenidos que venían de Europa, Restrepo construyó una metodología original para desarrollar los contenidos ilustrados. Si para varios de los ilustrados, la actividad docente fue considerada como marginal en su evolución intelectual, las funciones cumplidas en este campo por Restrepo permitió que para sus discípulos, los escenarios que en el caso de Santafé adquirieron señalada importancia para la difusión de los contenidos ilustrados- las bibliotecas, las tertulias, las sociedades de amigos del país, las expediciones científicas, la prensa, los viajes- en el caso de Popayán, por mediación de Restrepo, la enseñanza impartida por él desde, las aulas constituyó el principal vehículo para la difusión de esos conocimientos. Finalmente, mientras el grueso de quienes se habían aproximado al conocimiento científicos fueron ejecutados por España cuando recuperó el control de la Nueva Granada, Restrepo, gracias a la conjunción de circunstancias afortunadas, logró escapar al patíbulo.

Se trata, por lo tanto, de una personalidad multífacética, cuya prolongada vida activa transcurrió en diversos escenarios, tanto el pedagógico como el político, a través de los cuales su participación de Restrepo muy significativa tanto en la formación de las generaciones que participaron en la gesta de Independencia como también en la integración de esa entidad política incipiente que fue la nación colombiana. En este último caso, especialmente frente a la incorporación a la vida pública de un sector marginado de la población, el afrocolombiano.

En cuanto a la posición metodológica, se adopta una concepción de carácter hipotético-deductivo, que nos permitirá abordar la personalidad de Restrepo quien a partir de los elementos de la formación tradicional recibidos en su hogar y en el Colegio de San Bartolomé, discurrió posteriormente por los escenarios donde se debatieron los contenidos científicos y los provenientes del discurso liberal.

Rhela. Vol. 14. Año 2010, pp. $61-82$ 
En ese orden de ideas, se dividirá la exposición en edades, cada una de las cuales corresponden a etapas de la vida del prócer de acuerdo con las tendencias intelectuales prevalecientes. Para el análisis de ha contado con fuentes primarias originales e impresas, fuentes secundarias conocidas, y finalmente las obras completas de Restrepo.

\section{Su Vida}

Del matrimonio de Vicente de Restrepo y de Catalina Vélez Guerra nació en las cercanías de Envigado José Félix de Restrepo el 28 de noviembre de 1760. De esa unión nacieron cuatro hijos varones y dos hijas, y del segundo matrimonio de Vicente Restrepo, con Rita Granda, quedaron cinco hijos más. En la poco poblada provincia de Antioquia, una de las menos desarrolladas del virreinato, donde nació José Félix, al decir de Ospina Rodríguez, ${ }^{3}$ sólo había cuatro escuelas para niños. Por ello resulta significativo el hecho de que en una sola familia, la de José Félix, se hubieran formado cuatro doctores.

Ospina Rodríguez ya citado, se deleita en acentuar el carácter idílico de la sociedad donde surgió Restrepo. Sostiene que "Nuestros sencillos y laboriosos abuelos, privados de tantos elementos y facilidades de goce que en el presente siglo (el siglo XIX) nos han procurado industria europea y el crecimiento de nuestra riqueza, ¿eran más desgraciados que nosotros? No lo creo." ${ }^{4}$ No obstante, esa sociedad encubría profundos conflictos, como el de la posesión de la tierra, en virtud del cual, la ampliación de la frontera agrícola abrió el surgimiento de un proceso que permitió la expansión poblacional por el occidente de Colombia y fortaleció el desarrollo de la caficultura y el desarrollo fabril, y le dio a la región antioqueña un crecimiento vertiginoso, desconocido en otros sectores de Colombia.

A la temprana de doce años, en 1772, José Félix marchó a la capital de virreinato, luego de haber aprendido las primeras letras con un hermano de su madre, D. N Vélez quien además le había enseñado rudimentos en lengua latina. Esos conocimientos, que asombraron a quienes lo conocieron, le allanaron el ingreso al año siguiente al Colegio Mayor de San Bartolomé, donde se matriculo en la facultad de filosofía, donde se enseñaba el corpus aristotélico (lógica, metafísica, física, animástica), ajeno a los contenidos ilustrados. Para cursar los estudios en San Bartolomé Restrepo se había tenido que someter a

Ibídem, p 40.

4 Ibídem, p. 56. 
las informaciones, procesillo en virtud del cual los aspirantes debían demostrar, entre otras circunstancias, su pertenencia al estamento de origen español, El colegio de San Bartolomé, fundado por los jesuitas, había estado bajo el control de la Compañía hasta su expulsión en 1767, y ahora era dirigido por las autoridades virreinales y por el arzobispado, quienes se encargaban de nombrar a quienes lo administraban.

Sin embargo, luego del ingreso de José Félix al Colegio, soplaron vientos de renovación que le permitieron entrar en contacto con los contenidos ilustrados. En 1774, se abrió pasó, hasta 1779, la Reforma Provisional para los Colegios Mayores de Santafé instaurada por el Fiscal Moreno y Escandón. Este personaje, al mismo tiempo, había iniciado las gestiones para la creación de la primera universidad pública en la Nueva Granada, iniciativa que sólo habría de echar frutos posteriormente, durante la República de Colombia, y mientras Restrepo inspiraba la gestión educativa del naciente estado.

El contacto de Restrepo con los contenidos ilustrados le abrió el horizonte intelectual que proyectaría con singular éxito particularmente durante su estadía en Popayán, y luego en Medellín y en Bogotá, lo cual le permitió convertirse en el docente criollo más importante de su tiempo. También le facilitó el contacto con el discurso liberal con el cual brindó sus luces para la formación de la república y para construir el discurso a partir del cual se dio principio al proceso de liberación de los esclavos. Ello dentro de una sujeción irrestricta a la fe católica.

Las vicisitudes que recorrió la existencia de Restrepo pueden ser examinadas a través de la cronología que se incluye al final de este artículo. Por lo demás, su actividad como catedrático de destaca a través de lo que se ha denominado el momento de la observación, en tanto que su desempeño como funcionario y abogado se examina a través del llamado momento de la especulación

\section{José Félix Restrepo y la categorización de los intelectuales}

Cada generación propone un tipo de intelectual. Miguel Ángel Urrego, en un reciente trabajo ${ }^{5}$ reconoce que "en cada período hay un tipo dominante, el cual depende de las relaciones entre el capital cultural y económico y el grado particular de desarrollo de las clases y los proyectos políticos. Entendemos, igualmente, que pueden coexistir diversos tipos de intelectual en un mismo

\footnotetext{
5 URREGO, Miguel Ángel. (2002): Intelectuales, Estado y Nación en Colombia. de la guerra de los Mil Días a la Constitución de 1991. Siglo del Hombre Editores Universidad Central DIUC.
} 
periodo". VOVELLE Michel, igualmente, ha sido el editor de un texto en el cual destaca la relación entre los intelectuales y las diferentes ocupaciones. ${ }^{6}$

El apogeo del intelectual naturalista sacerdote no habría de durar mucho. Ya en 1794, cuando estalló el escándalo por la traducción de los derechos del hombre, los jóvenes que se fueron a formar a Europa eran seglares y algunos de ellos habían estudiado derecho. Se estaba perfilando un nuevo tipo de intelectual, el que habría de prevalecer por lo menos hasta 1808. Este intelectual absorbió, de una manera u otra, los saberes a que hemos hecho alusión. Se puede alegar que la combinación simultánea de abogado y naturalista no fue tan frecuente como se piensa, y que, en realidad, era más común el caso de quienes se dedicaban por separado al cultivo de las ciencias naturales y al derecho. Al fin y al cabo, el movimiento intelectual no se limitó a individuos como Francisco José de Caldas, Joaquín Camacho, José Ignacio de Pombo, Enrique Umaña. Sin embargo, su presencia se explica en la medida en que, cuando se abandonó el modelo del naturalista sacerdote, y ante la falta de médicos, en Santafé los únicos egresados de las facultades mayores que podían optar por dedicarse a la filosofía natural eran los abogados. Y, además, por la muy poderosa razón de que el fenómeno de la especialización, que empezaba a auspiciar la multiplicación de los saberes, todavía no era tan excluyente como para que un individuo inteligente pudiera albergar la gama de saberes que acabamos de ilustrar y manejarlos con la propiedad que se esperaba que lo hiciera quien pertenecía a la llamada república de los sabios.

Como se tratará de demostrar, cuando Restrepo desplegó todas sus energías en la conformación del ideal de nación durante la vigencia de la Republica de Colombia, ya había recorrido diferentes etapas o edades, que le conferían a su presencia en el foro colombiano un valor indudable, desde la perspectiva de los intelectuales ilustrados quienes, se consideraban, a sí mismos, los llamados por antonomasia para instalar el nuevo orden. Un orden que, a través del ideal de la ciudadanía, prometía igualdad, libertad y fraternidad para todos en una comunidad atomizada y sometida a los efectos de la sociedad estamental caracterizada por las profundas diferencias entre las castas y el sector de los criollos, empeñados en controlar el desarrollo del proceso político y en destacar una presunta superioridad de carácter cultural y económico sobre las capas sociales subalternas. José Félix actuó como un representante indudable de ese orden, e intentó, a través de sus iniciativas, la integración que creía necesaria para la construcción de una nación en ciernes.

6 VOVELLE, Michel (1995) El hombre de la Ilustración. Editorial Alianza, p. 28. 


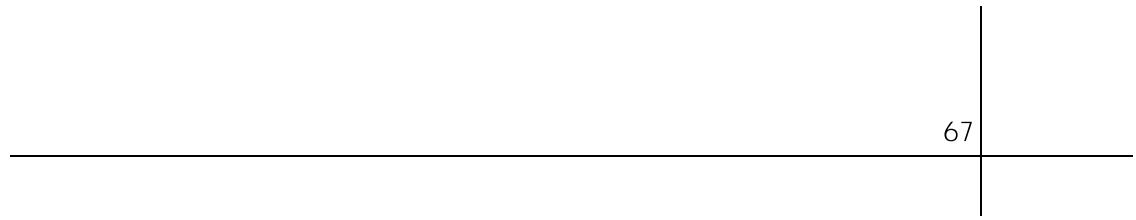

\section{El momento de la observación}

La iniciativa que en materia educativa desarrollaron los criollos antes de la terminación del período colonial fue la última etapa que recorrieron los conocimientos ilustrados para ser enseñados al interior de las aulas. A partir de la aprobación del plan de Medicina en 1805 se hizo evidente que los criollos habían tomado la delantera en materia educativa en relación con los estudios superiores. Se redactaron varios planes para el desarrollo de diferentes saberes, en especial en el campo de la minería, los criollos intervinieron en la supervisión de varios planes que se elaboraron para las instituciones de provincia, en Mompox y Medellín, y finalmente se abandonó el plan de estudios adoptado en 1779

Estas iniciativa habían tenido como escenario la ciudad de Santafé, pero en otras latitudes también se habían adelantado actividades tendientes a aclimatar los contenidos ilustrados. En Popayán, concretamente, la actividad desplegada por un exalumno de San Bartolomé, José Félix de Restrepo, a partir de 1782 en el Colegio Seminario de San Francisco de Asís, empezó a dar sus frutos, y abrió para Restrepo el período más fecundo en el campo de la pedagogía. Se formaron alumnos, como ya se mencionó, que posteriormente serían luminarias en el campo de la ciencia y de la política, como Caldas, Torres, Zea.

Así, en Santafé fracasaba el plan de Moreno y Escandón, no se implementaba el plan propuesto por el arzobispo virrey Caballero y Góngora, y no habían prosperado las iniciativas tendientes a crear cátedras estables como las de Química en el Colegio del Rosario o las de Bernardo Anillo en San Bartolomé, en Popayán. Los planes ilustrados en Santafé solo habían arraigado cuando José Celestino Mutis había presentado el plan para la facultad de Medicina en 1805, es decir más de veinte años después que Restrepo empezara a dictar la cátedra de filosofía en el Colegio Seminario de Popayán.

Así, si resulta sorprendente que los criollos, con respecto a los estudios superiores, hubieran tomado la iniciativa antes que en otros aspectos, como en la política, más sorprendente aún resulta que en provincia, un joven abogado de sólo veintidós años hubiera tomado la delantera en materia educativa.

Veamos cómo llevó a cabo Restrepo su propuesta. En primer lugar es de anotar que la cátedra de filosofía se siguió dictando de acuerdo con la estructura del corpus aristotélico. Es decir, la cátedra empezaba por la asignatura de Lógica, continuaba con la de metafísica y seguía con la física. La innovación consistió en que, sin salirse de la estructura tradicional, Restrepo no se sometió pasivamente a una repetición mecánica de los contenidos expuestos por el Estagirita, sino que presentó innovaciones en todas las asignaturas, innovaciones 
que mostraron una visión diferente a la que se había expuesto hasta ese entonces en la universidad neogranadina.

Es de advertirse que, en términos generales, la cátedra se dictó de acuerdo con los postulados ilustrados. Así, por ejemplo, en la enseñanza de la lógica ${ }^{7}$ se destacó la consecuencia negativa que para el aprendizaje del arte de aprender a pensar había tenido el abuso del silogismo; en metafísica Restrepo dejó ver la importancia que tenía para ese estudio el problema del alma; finalmente, en el estudio de la física, el joven profesor mostró claramente las ventajas que tenía la enseñanza de la ciencia moderna, como resultado de la observación de la naturaleza, en contraposición a la física aristotélica, de corte especulativo.

Se puede seguir la trayectoria que tuvo el pensamiento de Restrepo con respecto a cada asignatura para demostrar cuánto se apartó del pensamiento tradicional, de tendencia escolástica. El investigador Daniel Herrera Restrepo en sus comentarios ${ }^{8}$ sobre la obra de Restrepo precisa esos derroteros.

De todas maneras, es interesante observar cómo, si bien las obras publicadas hasta este momento y que resultan de apuntes tomados de clase, fueron dadas a conocer en tiempos de la república, se refieren de manera indudable a temas tratados durante la estadía de Restrepo en Popayán. Así, si bien la publicación de Las lecciones de lógica data de 1822, el texto recoge aspectos sobre los cuales Restrepo ya se había pronunciado sobre su contenido en la Oración de 1791 y en el Reglamento para las Escuelas de Antioquia. En ambos textos, Restrepo invita a seguir los postulados de una lógica ajena a "la inútil jeringonza de la Escolástica", y que evite "las cuestiones inútiles....prefiriendo siempre las útiles, a las de puro entendimiento; $y$, entre las útiles, las que tengan más relación con las necesidades del hombre". Por otra parte, también en ambos textos, "Restrepo hace seguir la enseñanza de la lógica por la enseñanza de las matemáticas."

Con relación a las Lecciones de fisica experimental, publicadas en 1825, es indudable que reflejan actitudes propias del ejercicio de la docencia en Popayán. Y ello, por cuantos alumnos de Restrepo como Camilo Torres y Francisco José de Caldas, antes de 1786 habían defendido proposiciones concernientes a la física moderna.

\footnotetext{
7 HERRERA RESTREPO, Daniel. (1989): "La lógica no ergotista de José Félix de Restrepo", en Cuadernos de filosofía latinoamericana. No. 40. Bogotá, Julio, pp. 110-163.

8 DE RESTREPO, José Felix, Comentários ver especialmente páginas 15-24; 65-73;

131-138.

9 Ibídem, p. 16.
} 


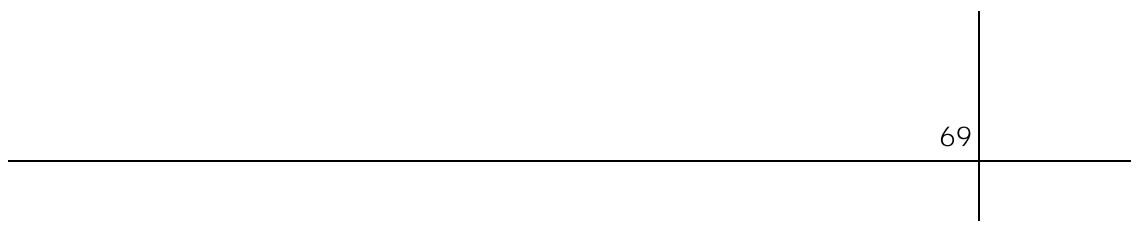

A continuación examinaremos las influencias que determinaron la posición intelectual de Restrepo mientras dictó la cátedra de filosofía tanto en Popayán como en Bogotá.

\section{La lógica}

Los elementos de la lógica se dividieron en cuatro partes: "De la simple aprehensión o idea", "Del juicio", "Del discurso o raciocinación", "Del método".

Sobre el texto de Restrepo se han señalado diferentes influencias, como lo anota Herrera Restrepo. En 1917 Juan Francisco Quijano ${ }^{10}$ le atribuyó la autoría de las Lecciones a Manuel Forero, quien a su turno caracterizó el texto como sensualista, de la escuela de Condillac, lo cual es erróneo. Varios autores ${ }^{11}$ se hicieron eco de la apreciación de Quijano, habiendo sido Gabriel Jaramillo quien por primera vez señaló esa identificación errónea.

Por su parte Rafael Gómez Hoyos ${ }^{12}$ acentuó la influencia ejercida por Aristóteles sobre Restrepo, sin advertir que para los filósofos de Port Royal el Estagirita fue un filósofo más, y no la primera autoridad en la lógica. En cuanto a la supuesta influencia que, según Jaramillo Uribe, ${ }^{13}$ ejerció Christian Wolf sobre Restrepo, debe aclararse que más que en relación con la lógica, esa influencia debe subrayarse en relación con las matemáticas. Sin embargo, mientras Wolf se muestra partidario del silogismo y apoya el llamado método de la fundamentación, Restrepo es enemigo rotundo de la utilización del silogismo y su método para encontrar la verdad es el analítico.

Tal parece entonces que la fuente de inspiración de Restrepo para sus Lecciones fue la Lógica o el Arte de Pensar aparecida en 1662 como de autor anónimo y que contó con decenas de ediciones en varios idiomas. Una de las razones que explican el éxito de la obra, además de su papel de difusora del movimiento teológico del jansenismo y del cartesianismo, fue el de haber llenado un vacío en los estudios en el campo de la lógica.

Ahora bien: la simpatía que experimenta Restrepo por la lógica de Port Royal se explica porque ésta se muestra como un instrumento no sólo de las

\footnotetext{
10 QUIJANO, Juan Francisco. (1917): "Historia de la filosofía en Colombia”, en Revista del Colegio Mayor del Rosario Volumen 13. Bogotá. pp. 356-364,492-496.

${ }_{11}$ De acuerdo con Herrera son Francisco M. Renjifo, Cayetano Betancur y Abel Sánchez,

12 GOMEZ HOYOS, Rafael. (1962): La revolución granadina. Bogotá, Instituto Colombiano de Cultura Hispánica. Tomo II. pp. 375-377.

13 JARAMILLO URIBE, Jaime. (1964) "José Félix de Restrepo, un discípulo de Wolff", en El pensamiento colombiano en el siglo XIX.Bogotá, Temis, pp. 372-377.
} 
ciencias sino de la vida, en la medida en que se procura que la lógica constituya una disciplina atrayente para los jóvenes.

Tal vez la diferencia más protuberante que se observa entre la lógica de Port Royal y la reflexión que sobre el particular realiza Restrepo es la insistencia que formula en relación con las matemáticas como complemento necesario de la lógica. Mutis había mostrado la importancia, desde la inauguración de la cátedra en 1762, de las matemáticas en los estudios superiores, tendencia que continuó subrayando Restrepo para quien las matemáticas constituían un paradigma del orden, rigor y exactitud que exigían los contenidos ilustrados.

Como se puede apreciar, existía una diferencia marcada entre la propuesta aristotélica para la enseñanza de la lógica y la forma como debía enseñarse esta materia de acuerdo con Restrepo, para quien, sin desdecir de los aportes del griego en la formulación de las elementos fundamentales de la disciplina, se apoya en otros criterios para complementar su enseñanza, en especial las matemáticas, materia que no se hallaba incluida en los estudios clásicos sobre la lógica.

\section{La metafísica}

A pesar de que Gómez Hoyos insiste en la influencia ejercida por la escolástica en Las lecciones de metafísica de Restrepo, Herrera ${ }^{14}$ señala que tal vez más que en ninguna otra disciplina, la metafísica resulta ser una obra ecléctica, en la cual la escolástica sólo ejerce una influencia señalada en la ontología. Por otra parte, la metafísica-dividida en cuatro lecciones, dedicadas al ente, la teología natural o de Dios, la psicología o tratado del alma humana, y el mutuo comercio entre el alma y el cuerpo-se alimenta en Restrepo con aportes provenientes de los cartesianos- Bossuet, Malebranche, Fenelón, el cardenal Polignac, aparte de Platón, Cicerón, Sócrates, autores clásicos citados para exponer la teología natural, la sicología y el tratado del alma y el cuerpo.

Por lo demás, Restrepo al abordar la metafísica, se sitúa al lado de los autores modernos para quienes la metafísica es una doctrina de principios y no una doctrina del ser, como lo había sido para Aristóteles. Por lo tanto, es necesario purgar a la metafísica de cuestiones estériles para orientarla al estudio del "ente y sus propiedades, de Dios en cuanto autor natural, el de la inmortalidad del

\footnotetext{
${ }^{14}$ DE RESTREPO, José Félix. (1978): Obras completas. Virginia, Universidad de Virginia, Secretaría de Educación y Cultura Departamental, p. 66 Ver, además, "La metafísica como ciencia de lo suprasensible en José Félix de Restrepo" En Cuadernos de filosofia latinoamericana. Bogotá. Universidad de Santo Tomás.
} 
alma y su comercio con el cuerpo", tal como lo dejó expuesto en su Reglamento para las escuelas de Antioquia (Art. 6). Sin embargo, tal vez la contribución más importante de Restrepo en el campo de la metafísica constituye, como ya lo anotamos, su fundamentación de la libertad humana.

\section{La física}

Sin desconocer la importancia conceptual que tienen los aportes de Restrepo con relación a la lógica y a la metafísica, en términos de su influencia sobre la ciencia, y de los discípulos que formó a su alrededor- basta con mencionar a Francisco José de Caldas- las huellas que dejó su labor como pedagogo son más claras en sus Lecciones de fisica experimental.

En estas materias, más que en las que ya tuvimos oportunidad de señalar, sus papel de innovador es más nítido, reaccionando en contra de Goudin, el escolástico exaltado en el Plan de Estudios de 1779, concebido para reemplazar al plan ilustrado de Moreno y Escandón y con el cual se intentó desconocer los alcances que tenían los contenidos modernos en los estudios superiores de Santa Fe.

El pensador que sirve de guía a Restrepo, pero solo en lo concerniente a la física, es el abate Juan Antonio Nollet, Aparte de él, Restrepo se apoya en otros científicos como Kepler, Paulian, Reamur, Wolf, Huygens, Newton, Muschenbroek. ${ }^{15}$ Para Herrera, "Restrepo supo recoger elementos en diversas formas para darle al conjunto una coherencia lógica y sistemática, a partir de un principio superior que no fue otro que el de la confirmación por parte de la razón, la experiencia y la utilidad pública. Restrepo fue el primero en hacerlo entre nosotros, pues ni siquiera Mutis lo logró...Las lecciones de física representan la normalización de la nueva ciencia en la Nueva Granada".

En esa tarea tan significativa, Las lecciones señalaron el paso hacia la ciencia moderna, de carácter cuantitativo, y en la cual las matemáticas, la geometría y la astronomía dejan de ser valores de carácter especulativo y en la que a través de la experiencia se somete lo que es susceptible de ser medido y objeto de cálculo.

\section{El docente y su método}

Sin embargo la tarea de Restrepo de la adaptación de la enseñanza de la ciencia en nuestro país se realiza de manera sosegada, sin la estridencia con la

\footnotetext{
15 Ibídem p. 133 Herrera menciona algunos de los textos producidos por estos científicos.
} 
que Moreno y Escandón y sobretodo Mutis llevaron a cabo sus polémicas en Santafé. Mientras Moreno fracasaba en sus intentos de adoptar su Plan Provisional para la enseñanza en los Colegios Mayores de Santafé, y en su pretensión de establecer una universidad pública, y Mutis se enfrascaba en una discusión con los dominicos acerca del heliocentrismo, Restrepo revolucionaba la enseñanza de una manera callada, acorde con su carácter conciliador y apacible. "El hábito de dominar las pasiones-anota Ospina ${ }^{16}$ Rodríguez- y seguramente una disposición feliz de su constitución originaria, le habían procurado un estado habitual de buen humor siempre igual, tranquilo y comunicativo".

Sobre el particular anota Herrera: ${ }^{17}$ "Para él, lo más importante es comprender, asimilar, difundir y naturalizar la nueva ciencia dentro de la serenidad, seriedad y rigor de la academia"

Sería exagerado sostener que Restrepo fue un innovador absoluto en su tarea de introducir los contenidos ilustrados en la cátedra del Colegio Seminario de Popayán. Pero sí se debe abonar a favor suyo las circunstancias de que las influencias que marcaron sus atisbos en la presentación de los contenidos ilustrados obedecieron a influencias adoptadas libremente, dentro de una concepción ecléctica, sin seguir una escuela de pensamiento definida. Del repertorio que le ofrecían los autores que llegaban a la Nueva Granada, Restrepo adoptó las que, de acuerdo con su criterio, poseían mayor valor desde el punto de vista intelectual y que también servían para llevar a cabo su pretensión pedagógica de llevar esos contenidos a sus alumnos de la manera más precisa y sencilla. "Este método, anota Ospina Rodríguez, ${ }^{18}$ que nadie antes de él practicó en el país, consiste en que el profesor se toma el mayor trabajo posible para inculcar en el ánimo de sus alumnos la doctrina que enseña....sin necesidad de texto o libro de estudio... porque las explicaciones del profesor...y el examen diario de la lección precedente, bastaban para grabar en el ánimo cuanto enseñaban". Y más adelante anota también Ospina: "Parecía profundamente penetrado del principio fundamental del arte de enseñar que atribuye al aprovechamiento y progreso de los estudiantes al hábito de fijar la atención y hace notar un hábito de lo agradable de la lección."

Estas orientaciones elementales constituyeron la propuesta pedagógica de Restrepo que, sin inspirarse en las tendencias en boga para la época- las que Restrepo no menciona-, velaba porque la asimilación de los contenidos previstos

\footnotetext{
${ }^{16}$ OSPINA RODRIGUEZ Mariano, op, cit., p. 25.

${ }^{17}$ DE RESTREPO Félix Obras Completas, op, cit., p. 137.

18 OSPINA RODRIGUEZ, op, cit., p. 137.
} 
en los planes de estudios se efectuaran sin contratiempos haciendo del aprendizaje un proceso agradable, donde el contacto persistente y sostenido con esos contenidos en virtud del ejercicio cotidiano de la atención constituían las claves de la formación.

\section{El Momento de la Especulación}

Obviamente, en un régimen donde la construcción del derecho se atribuía con mayor énfasis que en la norma, a la actividad del jurisconsulto, la posición que este asumiera frente al principal de los valores que constituye el contenido del derecho, o sea la justicia, era decisiva. Pese a que con la insistencia del discurso liberal en la importancia de la norma, y en que ésta debía orientar la actividad, no solo de los ciudadanos, y de los gobernantes, sino la de quienes derivaban su actividad de la interpretación de la norma, o sea los abogados, se debe aceptar que en el período en que actuó Restrepo siguió prevaleciendo la posición que consideraba que la construcción del derecho correspondía al jurisconsulto.

En una situación como ésa, la posición que adoptaran los jurisconsultos frente a la justicia era determinante. En medio de la fronda legislativa que guiaba su actividad, la elección que realizaba el jurisconsulto con respecto a la norma que debía aplicarse, guiado por el valor de la justicia era, insistimos, decisivas. Se cuentan algunas anécdotas acerca de relación de Restrepo con la justicia. ${ }^{19}$ Una de ellas nos relata cómo al final de la Colonia, en Popayán, Restrepo fue llamado como asesor a dirimir un pleito en el cual una de las partes era una viuda, madre de numerosa familia. Uno de sus biógrafos, Carlos Restrepo Canal, nos termina de relatar la anécdota:

"Dedicarle al doctor Restrepo detenido estudio al asunto, y tras de él llegó a adquirir el convencimiento de que no estaba la justicia de parte de la viuda, y decidió el asunto en contra de ella; más, pasados varios años, llegó para su conocimiento otro negocio en que se discutía un casó idéntico a aquel, y al estudiarlo halló que la ley que había aplicado en la sentencia proferida no era la que correspondía, llegando al convencimiento de que había caído en un involuntario error, y había perjudicado a la señora contra la cual había fallado. Indagó entonces a cuánto ascendía la suma perdida por dicha litigante, calculó a cuánto montaban los intereses de ella durante el tiempo transcurrido y con

\footnotetext{
${ }^{19}$ En otra ocasión pronunció un fallo adverso a los intereses del general José María Córdoba, quien por otra parte había sido favorecido con el voto de los demás miembros de la Corte Suprema. Más adelante se vio a Restrepo conversando por una calle concurrida de Bogotá, y se temió que ambos se trenzarían en un fuerte altercado. Pero no ocurrió así, y la conversación, según se dice, se realizó en términos de la mayor cordialidad.
} 
gran menoscabo de su fortuna pagó capital e intereses a la viuda, que se hallaba en situación penosa"

Sabemos que la importancia de la norma se empezó a aquilatarse con ocasión del advenimiento de la Primera República, y en especial con la redacción del Acta de Federación y de las constituciones provinciales, de las cuales, la segunda que se expidió en Antioquia, fue coautor el propio Restrepo. Sin embargo, las normas de jerarquía diferente a la constitucional seguían proviniendo en su mayoría de la legislación española, y así ocurriría a lo largo del siglo XIX, hasta que se fueron promulgando normas y códigos propios. Por lo tanto a Restrepo le correspondió actuar en un momento de transición donde todavía lo que prevalecía era la opinión del jurisconsulto, a quien le correspondía moverse en un maremagnum aún más complicado que durante la Colonia, pues debía conciliar lo dispuesto en la legislación española con legislación que se fuera expidiendo durante la República. De lo cual se infiere que las consideraciones debidas a la justicia debieron acrecentarse.

Ahora bien, ¿cuál concepción acerca de la justicia guiaba a Restrepo? Sea cual sea la noción precisa que lo inspiraba, sus concepciones debían remontarse a la antigüedad clásica, cuando Aristóteles expresó las diferentes categorías de justicia, la conmutativa y la distributiva. Mientras aquella se refería a la constante voluntad de dar a cada uno lo suyo, articulando las relaciones de individuo a individuo, de tal suerte que, por ejemplo, en una transacción comercial debía haber un cierto equilibrio entre el precio que se paga por una cosa y el valor de la misma, aquella regula las relaciones que debe haber entre la comunidad y cada uno de sus miembros, teniendo en cuenta las diferencias de méritos. Pero, además, no se puede olvidar la presencia de un valor que informa la justicia, como es el de la libertad. Con la fundamentación de la libertad culmina la metafísica de Restrepo. ${ }^{20}$ Para él con la "libertad humana se transforma la vida social." ${ }^{21}$ Además la defensa de la libertad debía manifestarse a través de hechos concretos, donde se vivenciara que la libertad y la justicia debían actuar como principios orientadores de la actividad humana, tanto a través de las pequeñas como de las grandes acciones.

La defensa de la libertad habrá de constituir el motor de su actividad, a través de las funciones de la docencia. ${ }^{22}$ Asume la defensa de la libertad de

\footnotetext{
${ }^{20}$ DE RESTREPO, Jose Felix. (2002): Obras completas. Notas de Daniel Herrera Restrepo. Bogotá. Universidad Santo Tomás de Aquino. USTA. Biblioteca Colombiana de Filosofia, pp. 65-73

21 Ibídem, p. 71.

22 Ibídem, pp. 72-73.
} 
pensamiento contra el dogmatismo que reinaba al interior de la universidad y que lo llevó, por ejemplo, a renunciar a la cátedra que regentaba en Santa Fe, en 1782, y a marcharse a Popayán; en la defensa que realiza a favor de los profesores laicos para examinar a los alumnos en los exámenes de grado en la Universidad Tomística, contrariando las órdenes de los directivos.

En tiempos de la República, en el campo de la educación abogó por la libertad de cátedra, siendo Director General de Estudios cuando se fundó en 1826 la Universidad Central, primera institución de estudios superiores de carácter público que se abrió en el país. Con la Universidad se fundó la Academia Nacional de Letras. En el Congreso de Cúcuta de 1821 culminó la lucha más importante de Restrepo a favor de la libertad como fue la Ley de Manumisión del 19 de junio de 1821, ley cuyos alcances se completaron durante la presidencia de José Hilario López, treinta años después. La iniciativa de Restrepo en contra de la esclavitud había comenzado con la Ley de Manumisión de los esclavos en la provincia de Antioquia, aprobada el 20 de abril de $1814 .{ }^{23}$

\section{La Esclavitud}

Sin lugar a dudas, la pieza más conocida y la más agudamente argumentada de Restrepo, no sólo desde el punto de vista jurídico, sino desde otras perspectivas, constituye el Discurso sobre la manumisión de los esclavos, que pronunció en el Congreso de Colombia en 1821, y que fuera publicado en la Imprenta del Estado al año siguiente.

Desde luego que sobre el proceso de liberación de los esclavos existen antecedentes, aparte del mismo proyecto redactado por Restrepo sobre el tema y aprobado el 20 de abril de 1814 y que el gobernante de la provincia de Antioquia para la época, el dictador Juan del Corral, dada la importancia de la determinación, prefirió que fuera aprobado por la Congreso Provincial. La propuesta presentada por Restrepo ante el Congreso de 1821 contiene varios de los elementos del proyecto redactado para la Provincia de Antioquia siete años antes, como que ambos se refieren sustancialmente a la libertad de vientres. Es de anotarse, además, que de acuerdo con Ospina Rodríguez, ${ }^{24}$ desde 1809 ya se había ocupado del tema en asocio con Antonio Villavicencio, sin que sobre el particular se conozca ninguna prueba documental.

Por lo demás, en otras latitudes ya se habían tomado providencias relativas

\footnotetext{
${ }^{23}$ SIERRA GARCIA, Jaime. (1988) "La Independencia de Antioquia", en Historia de Antioquia. Suramericana de Seguros. Jorge Orlando Melo.

${ }^{24}$ OSPINA RODRIGUEZ, op, cit., p. 17.
} 
a la esclavitud, tema en el cual Inglaterra ocupó una situación de vanguardia. En el propio siglo XVIII, en algunos de los Estados Unidos, concretamente en el norte de la federación, donde la esclavitud no era económicamente tan significativa como en el sur, se decretó su abolición. En Chile, donde tampoco la esclavitud era tan importante, se dictaron medidas sobre el particular.

Entre nosotros, en Cartagena se abolió en la constitución provincial de 1812. De manera que la propuesta de Restrepo no fue ni siquiera la primera que se promovió en el territorio nacional. Sin embargo, en relación con naciones de Latinoamérica donde la esclavitud constituía una institución influyente desde el punto de vista social y económico, la propuesta colombiana sí constituyó un antecedente digno de tenerse en cuenta. Así, por ejemplo, en países como Puerto Rico, Cuba, Brasil, Venezuela, Estados Unidos, Argentina, la esclavitud se suprimió después que en Colombia.

En esta historia de la esclavitud debe tenerse en cuenta que el camino que recorrió la cruzada abolicionista desde 1821 hasta la ley de manumisión del 21 de julio de 1851, que decretó la libertad de los esclavos, fue arduo y debió consultar los intereses de sectores esclavistas, especialmente de la antigua gobernación de Popayán, que se consideraban lesionados por las medidas. De esa suerte, hasta la expedición de la ley mencionada se vivió una gran incertidumbre con respecto a la esclavitud, incertidumbre que afectó las expectativas de los esclavos. ${ }^{25}$ Con la máxima "Ser generosos con los amos, sin dejar de serlo con los esclavos", se pretendió llegar a una transacción en virtud de la cual ni los amos partidarios de continuar con la esclavitud, ni los esclavos que deseaban obtener su liberación inmediata, quedaron satisfechos. En efecto: el artículo segundo de la ley que se redactó en 1821 en virtud del cual los hijos de las esclavas que nacieren a partir de 1821 serían libres en la medida que "trabajaran para los amos de sus madres durante 18 años", aplazó la libertad efectiva hasta 1839. Más adelante, por la ley del 29 de mayo de 1842, la libertad se aplazó por cinco años más, autorizándose, por añadidura, la reanudación del tráfico de personas. Estas dilaciones intensificaron el cimarronaje y mostraron la capacidad de los propietarios de esclavos para entorpecer el proceso de liberación.

Pese a lo anterior, no se puede desconocer que la medida impulsada por Restrepo, que conciliaba posiciones de la ética cristiana con la filosofía liberal, significó la culminación de su carrera de educador y de político, que, sin dejar

\footnotetext{
25 ROMERO JARAMILLO, Dolcey. Extraido desde internet el (23/6/2009) www// todacolombia.com. etnias/afrocolombianos.htm/ Dolcey Romero Jaramillo. Fecha de consulta $(15 / 03 / 2010)$
} 


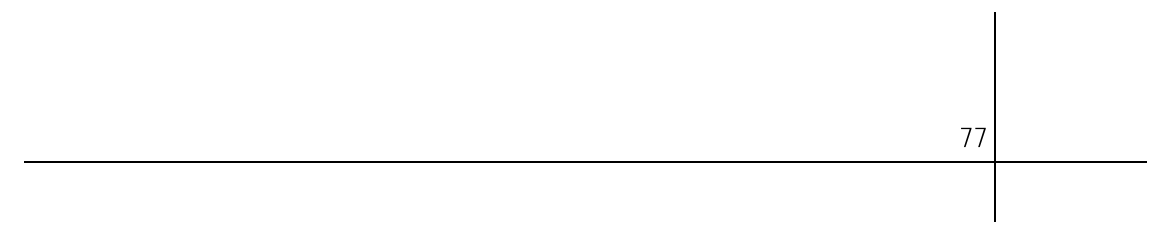

de adoptar posiciones conciliadoras- lo cual habla de manera elocuente del carácter de Restrepo- intentó ampliar la base social del sistema político que trataron de impulsar los criollos después de la Independencia en su propósito de construir la nación colombiana.

\section{Cronologia de Jose Félix de Restrepo}

1760. Nace en Envigado, Antioquia, hijo de Vicente Restrepo y de Catalina Vélez. Es bautizado el 28 de noviembre de 1760, en Medellín. Fueron sus hermanos Cristóbal, Carlos y Javier, que se dedicaron a las ciencias eclesiásticas.

1773. Después de realizar sus primeros estudios en Sabaneta, al lado de su tío, el presbítero Juan Cristóbal Vélez, se presenta en Santafé al Real Seminario de San Bartolomé el 23 de enero de 1773. José Félix es ya "superabundantemente ilustrado en latín" El rector, doctor Isabella, le otorga la beca el 11 de octubre. En San Bartolomé cursa filosofía y leyes.

1778. Es nombrado pasante en filosofía. Posteriormente es nombrado para la cátedra de la misma facultad. Allí enseña filosofía aristotélica.

1780. Obtiene el título de doctor en derecho el 7 de mayo. Restrepo se radica en Antioquia.

1782. El arzobispo de Popayán, en carta de mayo 18, le solicita se haga cargo de la cátedra de filosofía en el Colegio Seminario de Popayán. Enseña la cátedra durante tres años. Asimismo, para adquirir la práctica forense, asiste durante dos años al estudio del doctor don Manuel Antonio Rubianes, en Popayán.

1786. Se presenta ante el Real Acuerdo de Justicia en Santafé, donde es examinado. Es incorporado a la matrícula de abogados por la Real Audiencia de Santafé el 7 de septiembre.

1787. El 17 de enero es incorporado a la matrícula de abogados de la Real Audiencia de Quito. El 11 de agosto es designado Juez de Balanza de la Casa de Moneda de Popayán.

1788. Es nombrado Fiscal de la Junta de Temporalidades y de la Real Hacienda. Contrae matrimonio en Popayán, el 30 de mayo, con Tomasa Sarasti Ante y Valencia, hija del español Francisco Ignacio Sarasti y Aibar y de la payanesa María Joaquina Ante Valencia. Fueron sus hijos León Félix, María Josefa, Manuel María, Mariano y Cristóbal.

Rhela. Vol. 14. Año 2010, pp. $61-82$ 
1791. Es nombrado interinamente Asesor General del Gobierno de Popayán. Restrepo es además, alcalde de la ciudad de Popayán, y desempeña las funciones de Gobernador Político y de Subdelegado General de Rentas. El 24 de abril, con un célebre discurso, inaugura los estudios de filosofía y Ciencias Naturales en el Seminario de Popayán.

1795, El 5 de abril es nombrado catedrático de instituciones y derecho civil en el Colegio Seminario de Popayán. Desempeña la cátedra hasta el 19 de julio de 1798 .

1809. Se forma la junta revolucionaria en Quito. Restrepo, residente en Popayán, asiste a la tertulia de Mariano Lemos, donde se ventilan asuntos concernientes a la proclamación y libertad de la Gobernación de Popayán, tal como lo refiere José Hilario López.

1811. Restrepo, en compañía de sus alumnos en el Colegio de Popayán, repele un asalto de las tropas realistas al mando de Antonio Tenorio.

1812. Tomada Popayán por las tropas realistas de Juan Sámano, Restrepo se radica en Medellín, donde es nombrado vocal del cabildo. Desde allí promueve el establecimiento de una cátedra de gramática latina. Restrepo dirige, por su parte, un curso de filosofía.

1813. Restrepo influye para que el gobernante de Antioquia, Juan del Corral, se dirija al Congreso de las Provincias Unidas de la Nueva Granada para que decretara la libertad de los esclavos.

1814. El de abril se expide la ley que decreta a la libertad de los esclavos, disposición concebida de acuerdo con proyecto redactado por Restrepo. Se titulaba "Ley sobre la manumisión de la posteridad de los esclavos africanos y sobre los medios de redimir sucesivamente a sus padres, extendida y puesta para su sanción a la Cámara de Representantes del Pueblo por el Excelentísimo Dictador Ciudadano Juan B. del Corral. "La vigencia de la ley se extiende hasta 1816, cuando Antioquia es ocupada de nuevo por el ejército español.

1816. Ante las dificultades de la ocupación española, Restrepo, refugiado en Buga, es elegido por el Cabildo para negociar ante Juan Sámano el juramento de fidelidad al rey. Es propuesto para desempeñar una cátedra de matemáticas en Antioquia, pero la cátedra no llega a fundarse. 
1818. El 17 de enero, desde Medellín, escribe una misiva al gobernador de Antioquia solicitándole que "no se saquen esclavos para su venta en las provincias de Cartagena y Santa Marta"

1819. El Comandante y Gobernador de la Provincia, José María Córdoba, designado por el Libertador para liberar Antioquia, designa a Restrepo como Director de la Imprenta. Es encargado por el Gobierno de la Provincia para redactar un reglamento de las escuelas, que contempla desde la enseñanza primaria hasta los estudios superiores de gramática, latinidad, filosofía y teología, amén de otros asuntos de carácter administrativo.

1821. Es electo como diputado por Antioquia para concurrir al Congreso General el seis de mayo, instalado por Antonio Nariño, en su calidad de Vicepresidente. Restrepo es designado presidente de la corporación para el primer período reglamentario. En la sesión del 28 de mayo Restrepo presenta la moción, aprobada por unanimidad de votos, de considerar un proyecto para extinguir la esclavitud. La ley respectiva fue expedida por el Congreso el 19 de julio y recibió la sanción ejecutiva el día 21 del mismo mes. En virtud de la constitución de 1821 se crea la Alta Corte de Justicia. Como ministro de la alta corte es elegido Restrepo, quien además entra a formar parte del Consejo de Gobierno.

1823. El 11 de agosto se instala en Bogotá el supremo tribunal militar, del cual hacen parte Restrepo, Miguel Peña y Vicente Azuero.

1824. En el juicio seguido contra el coronel Leonardo Infante, por el asesinato del oficial Francisco Perdomo, Restrepo, ante la carencia de pruebas suficientes, solicita la degradación del grado militar y diez años de prisión.

1826. Es nombrado Director de Estudios en compañía de Vicente Azuero y Estanislao Vergara. El primer acto de la Dirección de Estudios es el establecimiento de la Academia Nacional. Recibe la notificación del gobierno de haberse fundado la Universidad Central, el 25 de diciembre. Con relación a las quejas que se presentaron en relación con la enseñanza de las doctrinas de Bentham y Tracy, los dos miembros de la Comisión General de Estudios Azuero y Vergara se pronuncian a favor de la utilización de los textos, en tanto que Restrepo se declara en contra de la utilización mencionada. En el juicio contra el general José María Córdoba, el acusado es absuelto. Solo el voto emitido por Restrepo es adverso. 
1830. Apoya al mandatario Joaquín Mosquera, cuyo gobierno es derrotado.

1831. El presidente general Domingo Caicedo lo llama a actuar en el Consejo de Gobierno. Restrepo es nombrado para el cargo Secretario de lo Interior.

1832. Muere José Félix de Restrepo el 23 de septiembre en Bogotá y es enterrado al día siguiente en la iglesia de Santo Domingo.

\section{CONCLUSIONES}

La figura de José Félix de Restrepo, formado durante la vigencia del Plan Provisional para los Colegios Mayores de Santafé, de Francisco Antonio Moreno y Escandón, plan de carácter ilustrado, nos muestra la trayectoria de un criollo que desde el principio de una larga carrera docente, defendió la introducción de los contenidos ilustrados dentro de las aulas universitarias, especialmente en el Colegio Seminario de San Francisco de Popayán, donde se formaron quienes, desde la Gobernación de Popayán, impulsarían el desarrollo de la ciencia y, más tarde, serían figuras de primera línea en el proceso de Independencia. José Félix de Restrepo ejemplifica, también, el papel destacado que tuvieron figuras nacidas fuera de Santafé quienes, también desde la provincia, impulsaron el proceso de introducción y adaptación del movimiento ilustrado en la Nueva Granada; en el caso de Restrepo esta participación se desarrolló principalmente a través de dos escenarios situados en el actual occidente de Colombia, Popayán y Medellín y también desde Santafé.

Restrepo es también un ejemplo del abogado naturalista que, desde posiciones diferentes en el mundo del saber, como el derecho y las ciencias naturales, construyó un tipo de intelectual nuevo, cuya trayectoria se vería truncada por el proceso de Independencia, cuando los representantes de la ciencia pasarían a ser absorbidos por los debates que culminaron en la organización del estado liberal defendido por los criollos.

Restrepo ilustra, además, el caso de un intelectual que, desde la ortodoxia católica, y a través de una trayectoria política moderada, impulsó una posición pedagógica y de hombre de estado que discurrió por una etapa de transición que pasó de la escolástica a los contenidos ilustrados y desde la Ilustración absolutista, impulsada desde la Corona, al estado liberal que se instituyó definitivamente luego de 1819. Como colaborador del vicepresidente Santander, Restrepo impulsó las reformas que permitieron acrecentar la intervención del estado en un proceso de escolarización y de reforma de la educación superior que señalaría el rumbo emprendido por el sector educativo durante el siglo XIX 
que permitió que el Estado fuera asumiendo el control del sector mencionado. A través de iniciativas como la de la libertad de vientres, Restrepo apoyó la incorporación, así fuera paulatina, de sectores de población que hasta entonces habían estado excluidos de la formación incipiente de la nación colombiana.

\section{FUENTES}

HERNÁNDEZ, de Alba. (1935) Vida y obras del Doctor José Félix de Restrepo. Bogotá. Imprenta Nacional.

RESTREPO, José Félix. (2002) Obras completas. Contextualización y notas por Daniel Herrera Restrepo. Bogotá, Universidad Santo Tomás. Facultad de Filosofía.

RESTREPO, José Félix. (1791): "Para el ingreso a los estudios de filosofía", en Papel Periódico. T. I. No. 45.

\section{REFERENCIAS}

AGUDELO SALINAS, Rocío. (2003): José Félix de Restrepo: libertador de los esclavos. Medellín, Educame. Alcaldía de Medellín.

BOTERO GOMEZ, Fabio. (1961) “José Félix de Restrepo”, en Obras completas de José Félix de Restrepo. Medellín.

GARCIA Julio César. (1935) “Universidad de Antioquia: Dr. José Félix de Restrepo,” en Revista de la Universidad de Antioquia No. 5. Medellín. Oct.-Nov.

GOMEZ HOYOS, Rafael. (1962) La revolución granadina. Bogotá, Instituto Colombiano de Cultura Hispánica. Tomo II.

HERNANDEZ DE ALBA, Guillermo. (1969-1985) Documentos para la historia de la educación en Colombia. Editorial Kelly. Bogotá.

HERNANDEZDE ALBA, Guillermo. (2007): Vida y escritos del doctor José Félix de Restrepo. Universidad de California, Imprenta nacional.

HERRERA RESTREPO Daniel. "La lógica no ergotista de José Félix de Restrepo", en Cuadernos de filosofia latinoamericana No. 40. Bogotá, Universidad de Santo Tomás. Facultad de Filosofía Julio.

JARAMILLO URIBE, Jaime. (1964) “José Félix de Restrepo, un discípulo de Wolff”, en $E l$ pensamiento colombiano en el siglo XIX. Bogotá, Temis.

JIMENEZ MEJIA Rodrigo. "José Félix de Restrepo" en Contemporánea No. 1 (MayoJunio). Bogotá.

Rhela. Vol. 14. Año 2010, pp. $61-82$ 
OCAMPO LOPEZ, Javier. (1982): "El proceso político, militar y social de la Independencia", en Manual de Historia de Colombia. Tomo II. Bogotá. Procultura. S. A. Instituto Colombiano de Cultura. Segunda Edición.

PAREDES, Jaime. (1943): José Félix de Restrepo. Medellín, Revista Universidad de Antioquia. No. 58. (abril-mayo)

QUIJANO, Juan Francisco. (1917): "Historia de la filosofia en Colombia", en Revista del Colegio Mayor del Rosario Vol. 13. Bogotá.

RESTREPO CANAL, Carlos. (1970): José Félix de Restrepo. Jurisconsulto, humanista y hombre de estado (1760-1839) Bogotá. Editorial Nelly.

RESTREPO CANAL, Carlos. (1960); "Informe sobre el lugar de nacimiento del doctor don José Félix de Restrepo", en Boletín de Historia y Antigüedades. Bogotá, Órgano de la Academia Colombiana de Historia. V. 47. No. 545-546.

RODRIGUEZ, Mariano. (1888) Biografia de José Félix de Restrepo http:biblioteca virtual -Antioquia. N. de a. edu.co. / pdf/11/11

SANCHEZ MONTENEGRO, Víctor. (1963): Félix de Restrepo: Profesor. Bogotá. Boletín Cultural y Bibliográfico. V. 6No. 12.

SIERRA GARCIA, Jaime. (1988): “Independencia de Antioquia," en Historia de Antioquia. Suramericana de Seguros. Jorge Orlando Melo.

SILVA, Renán. (1985): Escolares y catedráticos en la sociedad colonial. Informe final de investigación. Copia. Universidad Pedagógica Nacional. Centro de Investigaciones.

URREGO Miguel Angel. (2002): Intelectuales, Estado y Nación en Colombia. De la guerra de los Mil Días a la Constitución de 1991. Siglo del Hombre Editores Universidad CentralDIUC.

VOVELLE Michel.(1992): Introducción al hombre de la Ilustración. Madrid.Alianza Editorial.

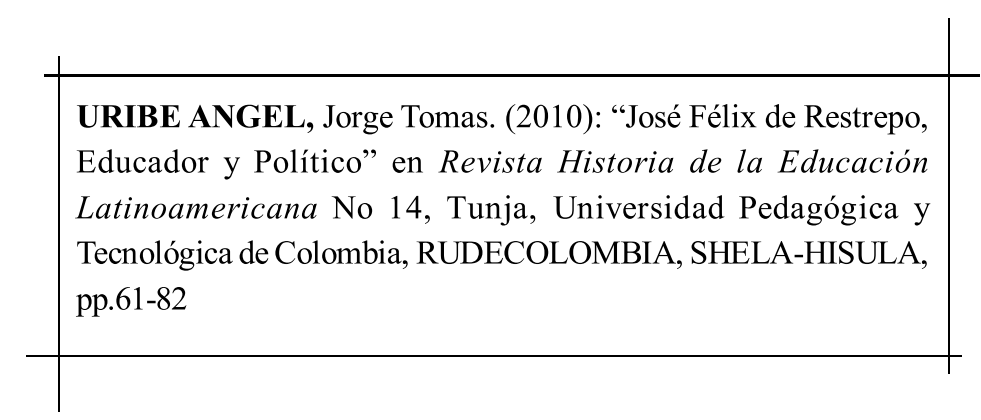

Rhela. Vol. 14. Año 2010, pp. $61-82$ 